Families in Society: The Journal of Contemporary Human Services

Copyright 1992 Families International, Inc.

\title{
Adultcentrism in Practice With Children
}

Christopher G. Petr

ABSTRACT: Adultcentrism is the tendency of adults to view children and their problems from a biased, adult perspective, thus creating barriers to effective practice with children. The author (1) examines the roots of social work's adultcentrism in history and developmental theory, (2) discusses how adultcentrism influences practice, and (3) considers ways in which practitioners can combat adultcentrism in practice.

$T$ HE SOCIAL WORK PROFESSION has a longstanding commitment to child welfare and improvement in the quality of life of children. But practice with children is a complex and demanding undertaking. A factor that complicates work with children is the simple fact that their perspectives are very different from those of the adult practitioners who work with them. Children are not adults-they have a different world view, different ways of communicating, different status and power, and different rights. Sensitive practitioners have long recognized these differences and sought creative ways to bridge the gaps. The task is akin to that of bridging cultural, racial, or gender differences. Effective practice with different ethnic cultures requires vigilant monitoring of potential ethnocentric bias and prejudice; similarly, the potential for sexism must be confronted in situations of gender difference.

The purpose of this article is to elucidate potential bias in work with children. The premise is that practitioners' effectiveness can be undermined by adultcentrism, a complex set of attitudes, values, and behaviors that can skew practitioners' relationships with children and thus negatively affect their work. Simply defined, adultcentrism is the tendency of adults to view children and their problems from a biased, adult perspective (Goode, 1986). This bias does not typically stem from some blatant, pernicious, or even conscious intent. Adultcentrism is subtle and, although the analogy is not perfect, it can be understood as being similar to ethnocentrism, which Sumner (1906) originally defined as "a view of things in which one's own group is the center of everything, and all others are scaled and rated to it." With respect to children and adults, adultcentric bias is evident when we measure children by adult standards, when we fail to suspend our assumptions about them, when we decline to see the world from their point of view. The negative consequences of adultcentrism can be the same as those of ethnocentrism: miscommunication (with children), inaccurate judgments (about children's intents and motivations), misuse of power (to limit chil-

Christopher G. Petr is Assistant Professor, School of Social Welfare, University of Kansas, Lawrence, Kansas. This article was adapted from a paper presented at the Annual Program Meeting of the Council on Social Work Education, March 1990, Reno, Nevada. 
dren's self-determination), and undermining strengths and competencies.

It may be difficult to endorse readily the idea that our relationships with children are subject to adultcentric bias, because most adults have children's best interests at heart and genuinely think of themselves and society as being child-centered. In fact, contemporary manifestations of adultcentrism are often nebulous and elusive, especially when compared with the drastic adultcentrism that has characterized adult-child relationships in Western European tradition. Long ago, children were regarded as little more than chattel whose purpose was to aid their parents and adult society. Economic and emotional dependency on adults was discouraged at early ages. A short life expectancy and harsh economic conditions mandated that children grow up fast and become absorbed into adult life and activities as soon as possible, even at six or seven years of age (Aries, 1962; Kadushin, 1980). Beginning in the 17 th century, however, notions about childhood began to change. This shift was due not to changes in demographic conditions or a reduction in child mortality but rather to the growing influence of Christianity on attitudes and customs (Aries, 1962). As Christianity began to emphasize the moral aspect of religion above its sacred aspects, attention was focused on the importance of children's education. Thus, gradually, "it was recognized that the child was not ready for life, and that he had to be subjected to a special treatment, a sort of quarantine, before he was allowed to join the adults" (Aries, 1962, p. 412).

By the late 19 th century, education and social welfare programs began to consider the unique developmental aspects of childhood. Child welfare policies and programs to protect and care for needy and delinquent youth flourished, in the early 1900s, including child labor laws, juvenile courts, and child-guidance clinics (Trattner, 1974). The study of childhood began in earnest in the late 1800s; by the middle of the 20th century, many sophisticated theories about child development had evolved. In more recent years, the legal and human rights of children have been recognized by the United Nations, and a "children's rights" movement is in place, as exemplified in the work of the Chil- dren's Defense Fund, a national advocacy organization, and the Children's Rights Report, a monthly newsletter of the American Civil Liberties Union.

Clearly, progress has been made and our society is generally less adultcentric and more child centered than ever before in history. Although the United States is in many ways a child-centered society, critics point out many contradictions and areas for continued improvement. For example, the United States is one of a handful of countries that have refused to ratify the United Nation's Convention on the Rights of the Child ("Child rights," 1990). Only 33\% of the families responding to a recent national survey stated that society places a great deal of value on children (Gallup Organization, 1988). Our infant mortality rate ranks 19th in the world, and reports of child abuse between 1979 and 1986 increased by 66\% (Children's Defense Fund, 1990). The United States has become the first society in history in which children are the poorest group in the population (Phillips, 1990). The fact that an organization such as the Children's Defense Fund exists is, paradoxically, an indictment of our society's disregard of children; if we truly valued children, society would not need such an organization. Many experts might argue that Benedict's (1934) commentary on American adult-child relationships made more than 50 years ago still applies today:

Our children are not individuals whose rights and tastes are casually respected from infancy, as they are in some primitive societies, but special responsibilities, like our possessions, to which we succumb or in which we glory, as the case may be. They are fundamentally extensions of our own egos and give special opportunity for the display of authority ( $\mathrm{p}$. 245).

Social work is not immune to these societal contradictions and ambivalences. Whereas social work has been vigilant in detecting and combating ethnocentrism and sexism, it has not adequately addressed adultcentric attitudes and tendencies among social work students and the larger society. For example, current Council on Social Work Education accreditation standards mandate specifically that the curriculum provide 
Families in Society

September 1992

content on ethnic minorities and women but make no mention of children. Generic practice texts include little, if any, significant material on practice with children (see Compton \& Galaway, 1989; Hepworth \& Larsen, 1990; Johnson, 1989; Morales \& Sheafor, 1989; Shulman, 1984). This situation is particularly vexing and perplexing in light of the fact that a significant proportion of graduates are employed in childrelated settings.

Analysis and confrontation of potential adultcentric bias can help practitioners remain vigilant in their determination to bridge the gaps between themselves and the children with whom they work. The following sections will (1) explore adultcentric bias in child-development theory, (2) discuss examples of adultcentrism in assessments and interventions, and (3) consider ways to combat adultcentrism in practice.

\section{Adultcentrism in Child- Development Theory}

Most social work practitioners are knowledgeable about the general tenets of child development. Major stage theories of child development are discussed in standard human behavior texts. On the one hand, these stage theories have helped adults, students, and the general public become more sensitive to the needs and capabilities of children at different ages. This enhanced sensitivity has influenced countless child welfare and educational programs, as developmental theory has been used to enhance the quality of life for children.

However, stage theories of child development are sometimes accorded such reverence that the voices of critics are not heard or appreciated. These critics maintain that society's subtle, yet powerful, adultcentric biases are revealed in the way that we study and learn about children. They assert that two subtle, yet central, adultcentric biases are embedded in stage theories of child development: (1) that children are incomplete and (2) that children are essentially incompetent.

Considering the first bias, that children are unfinished, incomplete, and in process, childdevelopment theory rests on the fundamental premise that children grow, develop, and mature in stages (Kagan, 1984). But this concept of developmental stages subtly implies that individuals who have not yet achieved the end stage of adulthood are necessarily and by definition undeveloped. In other words, children are incomplete: less knowledgeable, less serious, and ultimately less important than adults (Waksler, 1986). And if children are not fully adult, by implication they are not fully human (Goode, 1986).

Grotberg (1976) depicts this bias:

$\begin{array}{ll}\begin{array}{ll}\text { Children are } \\ \text { dependent }\end{array} & \text { Adults are } \\ \text { amoral } & \text { independent } \\ \text { egocentric } & \text { moral } \\ \text { illiterate } & \text { sociocentric } \\ \text { irrational } & \text { literate } \\ \text { emotionally unstable } & \text { rational } \\ \text { emotionally stable } \\ \text { unproductive } & \text { productive (p. 392) }\end{array}$

Although our society no longer views children as miniature adults, stage theory encourages us to view them as small, incomplete beings on their way to becoming adults. If all goes well, children will progress through the various developmental stages to the valued end of becoming well-adjusted, socially productive adults. Thus, stage theories of development become intertwined with the process of socialization or "acculturation" to the dominant, adult culture. The legitimate but perhaps overemphasized demands of the socialization process can lead adults to define children as vehicles for the transmission of social values (Denzin, 1977). This emphasis on the socialization aspects of adult-child relationships can lead to theoretical formulations of children that mirror the adult view that children are incomplete beings (Mackay, 1973).

The second adultcentric bias in stage developmental theory is closely related to the first. Beyond viewing children as incomplete, we view them as being essentially incompetent and incapable, because we measure their competence against our own. No matter what skill is mastered, what new knowledge is acquired, what developmental stage and milestone is reached, that competency is only briefly celebrated before our attention turns to the next rung on the ladder toward adult proficiency. We scale children according to how well they are mastering adult abilities. 
This is not to say that we should abandon stage-development theories or cease helping children grow and mature. But measuring children against the competence of adults is problematic in two ways. First, child-development theorists have consistently underestimated the abilities of children at all ages. The clear trend in developmental research is to "discover" competencies in children that developmental experts previously had not thought possible. This is particularly true in the area of infantdevelopment research, which has experienced rapid growth in the past two decades. Infants were traditionally assumed to be the most incompetent and incapable of children. Mahler, Pine, and Bergman (1975) went so far as to describe newborns up to three months old as "autistic," believing that young infants basically did not interact with their environments. Research has shown that nothing could be further from the truth. For example, Stone, Smith, and Murphy (1973) collected scores of research articles documenting infant capabilities, including neonate motor, sensory, perceptual, and learning abilities. In a more recent text, Snow (1989) states,

even at birth infants possess remarkable abilities. We used to believe that babies were blind at birth. We now know that the newborn can not only see, but is capable of other sophisticated functions (p. 8).

This tendency to underestimate children's competencies is documented in recent qualitative research and so-called resiliency studies. Regarding the former, a recent assessment of qualitative research with children (Fine \& Sandstrom, 1988) concluded that these studies revealed that children are more mature and capable than expected:

Some studies find that children are much more sophisticated than we have given them credit for being. They are more verbally effective, emotionally considerate, or socially knowledgeable. They are more "mature" than we as "grownups" believe. We know of no study that has found that children are more "childish" than we have given them credit for (p. 72).

The resiliency studies challenge child development's long-held assumption that early experi- ence has a permanent impact on a child's later development of competence. In a thorough review of longitudinal studies that addressed this issue, the author concluded that although early experience can have serious negative effects, such outcomes are in no way way universal, in that many studies have demonstrated that many children make impressive recoveries. Although the past is important, the present is itself a potent force that pressures each person to adapt and come to terms with it (Clapp, 1988). These impressive recoveries reinforce the notion that children have more strengths and competencies than we typically attribute to them.

The second way in which the competence bias is problematic is that our stage theories are so focused on the socialization and maturing process that we fail to view children as beings with their own knowledge, skills, and culture. We know about children, but do we know children? Just as the dominant white culture now strives to view the values and knowledge of minority cultures as being merely different from, not inferior to, white culture, adults need to view children as having a culture that is merely different from, not "less than," adult culture. However, adults seldom view children as children. We seldom study children in their natural environments and from their own perspective of what is important. When such studies have been undertaken, the results have been surprising. For example, Glassner (1976) studied grade-school children during unsupervised recess at a public school in St. Louis. Although the main purpose of the study was to determine the extent of integration within the student population (which he found to be quite high), an unexpected finding was the degree to which a separate "kid society" existed, complete with its own norms, hierarchy, and subgroups. This society focused almost exclusively on itself, with little or no interaction with adults. In fact, Glassner claimed that he never heard a child talk about teachers, classroom activities, parents, or home life.

\section{Adultcentrism in Assessment And Intervention}

Stage theories of child development are a major foundation of practice with children. The 
Families in Society

September 1992

adultcentric aspects of stage theory are intensified in assessments as a result of professionals' ongoing tension between being a "helper" while also representing the larger society's interest in social control and socialization (Pincus \& Minahan, 1973; Specht, 1988). Social workers engage children in various settings, including residential institutions, mental health centers, schools, court probation offices, child protection, foster care, and adoption agencies. In many of these settings, the social worker is something of a "socialization expert." The professional is asked by the parent, teacher, or court system to diagnose the child, then "shape up" and "correct" the child-in effect, to socialize the child to adult society's standards. This agenda can magnify the effects of adultcentrism so that social workers must be constantly vigilant in combating the subtle adultcentric agendas of their agency contexts.

\section{Family therapy models, although widely diverse in orientation, generally share a systems orientation that can lead to devaluation of children's perceptions.}

In child mental health assessments, judging normal childhood behaviors as abnormal and pathological is a danger. In the child and adolescent section of the Diagnostic and Statistical Manual of Mental Disorders (American Psychiatric Association, 1987), one finds many diagnostic indicators that could be applied to almost any child. For example, the criteria for oppositional disorder can be viewed as describing normal adolescence. A child must exhibit at least five of nine behaviors, including "often argues with adults" and "often touchy or easily annoyed by others." What normal adolescent isn't touchy and doesn't argue? Although the manual does state that the behavior must be exhibited "more frequently than most people of the same mental age," no guidelines are provided about how "most people" behave. Thus, a child can be diagnosed with any number of mental disorders for exhibiting normal behaviors more frequently than one professional thinks is average for the child's mental age. Might not some professionals be diagnosing childhood itself?
In a humorous yet scathingly perceptive parody of child assessment called "The Etiology and Treatment of Childhood," Smoller (1986) exposes this tendency. Although written as satire, Smoller shows how stage-development theory's adultcentric themes of incompleteness and incompetence intertwine with a socialization agenda to produce an adultcentric case plan. Smoller states that the "clinical features of childhood" include congenital onset, dwarfism, emotional lability and immaturity, knowledge deficits, and legume anorexia. The causes of childhood include the psychological-based theory of "learned childishness," which postulates that individuals who are treated like children eventually give up and become children. Despite intensive treatment, many victims of childhood remain children. Smoller presents the following case as "typical."

Billy J., age 8, was brought to treatment by his parents. Billy's affliction was painfully obvious. He stood only 4'3" high and weighed a scant 70 pounds, despite the fact that he ate voraciously. Billy presented a variety of troubling symptoms. His voice was noticeably high for a man. He displayed legume anorexia and, according to his parents, often refused to bathe. His intellectual functioning was also below normal-he had little general knowledge and could barely write a structured sentence. Social skills were also deficient. He often spoke inappropriately and exhibited "whining behavior." His sexual experience was non-existent. Indeed, Billy considered women "icky."

His parents reported that the condition had been present from birth, improving gradually after he was placed in a school at age 5 . The diagnosis was "primary childhood." After years of painstaking treatment, Billy improved gradually. At age 11, his height and weight have increased, his social skills are broader, and he is now functional enough to hold down a "paper route" (p. 9).

When intervening with children, practitioners must pay particular attention to issues of defining the client, self-determination, and social control. Is the client the child, the parent, or the teacher? What are the ethical and practical limits to self-determination in work with children? How much social control of children is warranted? Although these issues are extant across all practice methodologies, behavior modification and family therapy illustrate such issues particularly well. 


\section{Adultcentrism}

Behavior therapy is a powerful and often effective methodology that is taught in many schools of social work (Association for the Advancement of Behavior Therapy, 1981). Yet it remains controversial with respect to issues of control and its impact on children's self-directed behavior. Its supporters emphasize its commitment to empiricism and measurable outcomes (Thyer, 1989), whereas critics question its emphasis on social control (Schrag, 1978) and other ethical issues (Stolz, 1978). Although a comprehensive review of the controversy is beyond the scope of this article, social work's commitment to self-determination and clientcentered practice requires that professionals be aware of the adultcentric potential of behavior theory and its application.

In a recent national study of supposedly exemplary school programs for children with behavioral and emotional disorders, the authors identified a "troubling pattern" they called "the curriculum of control" (Knitzer, Steinberg, \& Fleisch, 1990):

The curriculum emphasis is often on behavioral management first, learning, if at all, second. Central to many of the classrooms we visited was a great concern with behavioral point systems. Yet often, these seemed largely designed to help maintain silence in the classroom, not to teach children how better to manage their anger, sadness or impulses (p. xii).

In a review of outcome research on behavior therapy with children, Graziano and Bythell (1983) questioned whether the modality is client centered or more focused on adult agendas of socialization and social control. Even when behavioral changes occurred, they questioned whether those changes were of personal or clinical significance for the youth involved. By way of example, they cited programs for quiet children, whom adults decide are socially withdrawn and in need of behavioral intervention without consideration of whether their quietness was problematic for the child.

Family therapy models, although widely diverse in orientation, generally share a systems orientation that can lead to devaluation of children's perceptions. As Johnson (1986) points out in her critique of family therapy, "a fairly obvious dilemma is that some interventions may foster the best interests of one family member, at the same time, countervailing those of another member" (p. 303). When agendas clash, family workers understandably can become confused about who is the client. Because children are less verbal and less powerful in the family hierarchy than are parents, the problem definition and treatment plan can be overly influenced by the adults, unless the practitioner moves strongly to incorporate and empower the children. Although this issue has recently begun to be addressed (see The Family Therapy Networker, 1991), family systems theories have not typically identified this issue or encouraged therapists to seek out, validate, or legitimize the child's perspective (Hoffman, 1981).

In summary, the danger in practice with children is to overidentify with the goals and point of view of the adults. This danger is intensified by the agency context, which often emphasizes social control, and by practice methodologies, which implicitly legitimize the adult point of view. Children have relatively little power in the world; adults exercise their power over children in families and in agencies. Thus, practitioners working with children must be vigilant in combating adultcentric forces.

\section{Recommendations for Combating Adultcentrism}

The following paragraphs offer specific suggestions on ways in which practitioners can avoid adultcentric views. Although some of these suggestions may not be new to experienced practitioners, they nevertheless serve as useful reminders, while orienting beginning practitioners to some guiding principles for child-centered work.

First, practitioners need to take time to learn about and value children as children. A powerful way to combat any bias is to enter, to the extent possible, the world of the other. In work with children, this means suspending our usual adult-child interactions long enough to observe children as they are in their natural settings such as playgrounds, backyards, video parlors, and malls. What are children like when they are not responding to adults? What is important to them in their own world? By routinely taking the time 
to get outside and beyond our usual modes of interaction, we gain insight not only into their worlds, but into our own subtle biases. Through the process, we may even rediscover the playful, childlike parts of ourselves.

A second way in which practitioners can empower children and avoid adultcentrism is routinely to conduct individual interviews with children, even when the presenting problem and theoretical orientation of the practitioner and agency favor a family systems approach. In this way, the child's perspective is included in the assessment and intervention, assuming that the practitioner is skilled in commuricating with children. Thorough discussion of how to interview children is beyond the scope of this article, but it should be noted that one does not interview children in the classic sense. Our adult verbal communication style does not mesh with a child's preference for communicating through play, metaphor, drawing, and physical activity. If we insist that a young child sit quietly and talk with us about a problem, even if we do so individually, we may not obtain much valuable information.

\section{One does not interview children in the classic sense. Our adult verbal communication style does not mesh with a child's preference for communicating through play, metaphor, drawing, and physical activity.}

Intrafamilial sexual abuse is one of the few family problem areas for which an individual interview with the child is recommended in the literature. It is widely recognized that children will not generally reveal incidents of incest in a family context-the prohibitions are just too strong (Sgroi, 1982). But might this be the case for many other problems as well? Why do we so often assume that children will provide us with their perspective and opinions about school problems, alcohol and drug use, their parents' behavior, and other issues during family meetings? If time is set aside for individual interviews with the child, not only will new information be obtained but the child's investment in goals and problem definition will enhance his or her participation and motivation in therapy.
Thirdly, practitioners can operationalize the cardinal social work value of self-determination by involving a child more fully in the decisions made by practitioners and other adults that directly affect his or her life (Bush \& Gordon, 1982). This does not mean that practitioners should blindly allow children to be totally self-determined. As with adults, self-determination needs to be limited with respect to the client's capacity and respect for others' rights. But practitioners should diligently and routinely include children's perspectives and wishes in the decision-making process.

There are at least four valid reasons to do so. First, in many circumstances, children have interests that are appreciably different from those of their adult caretakers (Melton, 1982). Examples of conflict of interests include parents or guardians admitting their children to mental hospitals, placement decisions in child welfare, and divorce custody. Second, ethical considerations stemming from the value of respecting children and equalizing power differentials compel us to pay attention to children's views. In so doing, we communicate confidence in their strengths and ability to solve problems. Third, solicitation of children's views can enhance their satisfaction with the ultimate decision. For example, foster children who had a voice in their placement reported significantly greater satisfaction with their placements than did those who had no input (Bush \& Gordon, 1982). Finally, children's views and preferences can inform public policy. For example, whereas adults have long been ambivalent about the role of institutions in the care of children (Petr \& Spano, 1990), children unequivocally prefer noninstitutional placements (Bush, 1980). Contrary to the predominant adult, professional view that most foster children want to be adopted, perhaps as many as $50 \%$ of foster children do not want to be adopted under any condition (Bush \& Gordon, 1982).

The final recommendation is that practitioners support changes in social work research and education. In the research arena, studies on the effectiveness of programs often fail to include the perspective of the children who are directly affected. Recent studies of adoption that focused on data obtained from social workers, parents, and records are a case in point (Barth, 1988; Kagan \& Reid, 1986; Reid, Kagan, Kaminsky, \& Helmer, 1987). Although these studies yielded important 
information about adoption prac tices, the results would have been enriched, perhaps even changed, if the researchers had included the opinions and perspectives of children themselves. In their review of permanency-planning research, Barth and Berry (1987) acknowledge this shortcoming in research and argue that data about children's satisfaction should be incorporated into permanency-planning research as one of the indicators of the suitability of placement. Practitioners should support utilization of both quantitative and qualitative methodologies (Cook \& Reichardt, 1979) in research designs. Although many ethical and logistical barriers must be overcome before engaging in qualitative methods such as participant observation with children (Fine \& Sandstrom, 1988), these approaches can be powerful weapons against adultcentrism because of the emphasis placed on immersing oneself in the world of the subject in order to know and understand that world better.

Practitioners can support changes in educational curriculum that address these issues in research classes. In other areas of the curriculum, content on child-development theory should include a critique of the adultcentric bias of stage theories, along the lines articulated in this article. Stern (1985) and Gergen (1983) offer frameworks for exposing practitioners to nontraditional development theories, which emphasize the power of the individual as an autonomous, active agent. This emphasis is also found in much of the general systems literature and has strong implications for the worker-client relationship (Petr, 1988). Classes and texts need to address the specific issues in working with children as a special population, similar to the way in which ethnic minorities are considered unique populations. The content of this material should include (1) specific ways to communicate with and understand the language of children; (2) a clear acknowledgment of and confrontation with the socialization and social-control aspects of work with children as these issues are manifest in various practice settings and methodologies as well as the implications of these issues with regard to self-determination and empowerment, and (3) specific exercises and activities that thrust students into the world of children (playgrounds, video parlors, day-care centers) so that they can better know, not just know about, children.

\section{REFERENCES}

American Psychiatric Association. (1987). Diagnostic and statistical manual of mental disorders (3rd ed., rev.) Washington, DC: Author.

Aries, P. (1962). Centuries of childhood. London: Jonathan Cape.

Association for the Advancement of Behavior Therapy. (1981). Graduate study in behavior therapy: Social work departments. New York: Author.

Barth, R. P. (1988, Winter). Disruption in older child adoptions. Public Welfare, 46, 23-29.

Barth, R. P., \& Berry, M. B. (1987, March). Outcomes of child welfare services under permanency planning. Social Service Review, 61, 71-90.

Benedict, R. (1934). Patterns of culture. Boston: Houghton Mifflin.

Bush, M. (1980). Institutions for dependent and neglected children: A therapeutic option of choice or a last resort? American Journal of Orthopsychiatry, 50, 239-255.

Bush, M., \& Gordon, A. C. (1982). The case for involving children in child welfare decisions. Social Work, 27, 309-314.

Children's Defense Fund. (1990). Children 1990: A report card, briefing book and action primer. Washington DC: Author.
Child rights become law. (1990). Action for Children, $5(2), 1,4$.

Clapp, G. (1988). Child study research: Current perspectives and applications. Lexington, MA: D. C. Heath.

Compton, B. R., \& Galaway, B. (1989). Social work processes (4th ed.). Belmont, CA: Wadsworth.

Cook, T. D., \& Reichardt, C. S. (Eds.). (1979). Qualitative and quantitative methods in evaluation research. Beverly Hills, CA: Sage Publications.

Denzin, N. K. (1977). Childhood socialization. San Francisco: Jossey-Bass.

The Family Therapy Networker. (1991). 15(4).

Fine, G. A., \& Sandstrom, K. L. (1988). Knowing children: Participant observation with minors. Newbury Park, CA: Sage Publications.

Gallup Organization. (1988). A study of the parental experience of American parents. Chicago: Family Resource Coalition

Gergen, K. J. (1983). Toward transformation in social knowledge. New York: Springer-Verlag.

Glassner, B. (1976). Kid society. Urban Education, 11(1) 5-21.

Goode, D. (1986). Kids, cultures, and innocents. Human Studies, 9, 85-106.

Graziano, A. M., \& Bythell, D. L. (1983). Failures in 